\title{
Is this a new type of primary prosopagnosia, both progressive and apperceptive?
}

This article was published in the following Dove Press journal:

Neuropsychiatric Disease and Treatment

17 April 2012

Number of times this article has been viewed

\author{
Azusa Sugimoto' \\ Shinichi Koyama ${ }^{2}$ \\ Akira Midorikawa ${ }^{3}$ \\ Akinori Futamura' \\ Kiichi Ishiwata ${ }^{4}$ \\ Kenji Ishii ${ }^{4}$ \\ Michael W Miller ${ }^{5}$ \\ Mitsuru Kawamura' \\ 'Department of Neurology, Showa \\ University School of Medicine, Tokyo, \\ ${ }^{2}$ Design Psychology Unit, Department \\ of Design Science, Graduate School \\ of Engineering, Chiba University, \\ Chiba, ${ }^{3}$ Department of Psychology, \\ Faculty of Letters, Chuo University, \\ Tokyo, ${ }^{4}$ Positron Medical Center, \\ Tokyo Metropolitan Institute of \\ Gerontology, Tokyo, ${ }^{5}$ Medical \\ Sciences Training Programme, Faculty \\ of Medicine, University of Tokyo, \\ Tokyo, Japan
}

Correspondence: Mitsuru Kawamura Department of Neurology, Showa University School of Medicine, I-5-8 Hatanodai Shinagawa-ku, Tokyo I42-8666, Japan

Tel +8I 3378487 I0

Fax +81337848710

Email kawa@med.showa-u.ac.jp
Abstract: Prosopagnosia, the inability to recognize faces, has a history going back to Charcot and Hughlings-Jackson, but was first named by Bodamer in 1947. Its anatomical loci are still unclear. However, progressive prosopagnosia is normally linked to right dominant temporal lobe atrophy, and diagnosed as part of frontotemporal lobar degeneration. Here we report a case of prosopagnosia linked to posterior cortical atrophy. Although case reports of posterior cortical atrophy-prosopagnosia do already exist, it is normally described as an accessory symptom. The interest of our own posterior cortical atrophy patient, possibly the first such case, is that he had a rare apperceptive type of prosopagnosia unrelated to the associative, frontotemporal lobar degeneration-type.

Keywords: dementia, Alzheimer's disease, frontotemporal lobar degeneration, neuropsychology

\section{Introduction}

Progressive prosopagnosia was first reported by Evans et a $\mathrm{l}^{1}$ following the work of Tyrrell et al. ${ }^{2}$ These cases have right temporal lobe atrophy. As to left temporal lobe atrophy: it is known that progressive fluent aphasia, also known as semantic dementia, is a subtype of frontotemporal lobar degeneration. ${ }^{3}$ Progressive prosopagnosia, on the other hand, may represent a right hemisphere type semantic dementia. ${ }^{1}$

Posterior cortical atrophy (PCA) presents visual agnosia including prosopagnosia. ${ }^{4,5}$ But in most PCA cases the atrophic changes start with the occipitoparietal lobe where visuospatial information is processed. ${ }^{4,5}$ Thus prosopagnosia reports as an accessory symptom. ${ }^{4,5}$

The first ventral-type PCA report was by Beversdorf and Heilman, ${ }^{6}$ and the patient presented alexia for music and words with left dominant brain atrophy. Here we report, what we believe is a first case of right dominant ventral PCA, with a primary prosopagnosia that is both progressive and apperceptive. Apperceptive type prosopagnosia involves disability for: unknown face matching, recognition of facial expression, sex, and age. The associative type patient does not have these problems but cannot name famous faces, because of an inability to match visual perception to memory. ${ }^{7}$

We describe our case vis à vis established descriptions of prosopagnosia, and summarize the findings in a schematic diagram. Furthermore, we discuss the relationship of PCA's neuropsychological symptoms to atypical dementia.

\section{Case report}

A 58-year-old, right-handed man developed difficulty in recognizing familiar people. The case came to our attention 3 years after appearance of the first symptoms. At first, 
the patient devised polite social strategies to get around his problem, but it then become too difficult for him to manage. Finally, when he failed to recognize his own family members, he visited the ophthalmologist. The evaluation was normal. He continued working as an engineer, although he needed assistance recognizing people. Furthermore, he devised an ingenious strategy for recognizing family members in a given situation. Each member of the family used his/her own teacup with a picture on it, and each had a particular seat at the dinner table. By allocating cups to sitting places he was able to establish to whom he was speaking at family meals. He was also able to drive around without getting lost. Finally he realized something was wrong and came to the hospital. His general physical condition was good, but a neurological examination revealed left lower quadrantanopia, but no signs of Gerstmann's or Bálint's syndromes. There was no rigidity or Parkinsonism.

His Mini-Mental State Examination (MMSE) score was $28 / 30$ points with errors in subtraction and copying of a double pentagon. He had severe prosopagnosia and disability in famous face naming, famous face pointing, discriminating and matching unfamiliar faces, and recognizing facial expression, sex, and age. He also presented picture agnosia. Primary visual functions and recognition of symbols including characters and words were relatively preserved. He showed mild, left, hemispatial agnosia. Table 1 shows his visual perception test for agnosia as used for Japanese patients. ${ }^{8}$ He presented no obvious signs of aphasia, and there was no ideomotor, ideational, or constructional apraxia. He was able at that stage to manage ordinary life and his Barthel Index ${ }^{9}$ score was 100/100.

Figure 1 shows temporo-parieto-occipital lobe atrophy with right-side dominance on magnetic resonance imaging: ${ }^{99 m}$ Tc-ethyl cysteinate dimer SPECT using the easy Z-score imaging system (eZIS) ${ }^{10}$ showed decreased blood flow in the temporo-parieto-occipital lobe (Figure 2).

On follow-up examination, visual agnosia gradually progressed. Positron emission tomography (PET) was carried out 7 months after first examination: ${ }^{18} \mathrm{~F}$-fluorodeoxyglucose PET revealed right hemihypometabolism, especially from

Table I Visual perception test for agnosia ${ }^{8}$

\begin{tabular}{|c|c|c|c|c|}
\hline Test & $\begin{array}{l}\text { Errors on first examination } \\
\text { (percentages) }\end{array}$ & $\begin{array}{l}\text { Errors } 14 \text { months later } \\
\text { (percentages) }\end{array}$ & Tasks & (Mean \pm SD) \\
\hline \multicolumn{5}{|l|}{ Face recognition } \\
\hline Famous face naming & $16(100)$ & $16(100)$ & $/ 16$ & $(0.8 \pm 1.95)$ \\
\hline Famous face pointing & $13(81)$ & $16(100)$ & 116 & No mean $\pm S D$ for this item \\
\hline Unknown face discrimination & $7(88)$ & $8(100)$ & 18 & $(0.6 \pm 1.12)$ \\
\hline Unknown face matching & $6(100)$ & $6(100)$ & 16 & $(0.1 \pm 0.27)$ \\
\hline Perception of facial expression & $5(83)$ & $6(100)$ & 16 & $(0.0 \pm 0.14)$ \\
\hline Perception of sex & $6(75)$ & $8(100)$ & 18 & No mean $\pm S D$ for this item \\
\hline Perception of age & $8(100)$ & $8(100)$ & 18 & No mean $\pm S D$ for this item \\
\hline \multicolumn{5}{|l|}{ Object recognition } \\
\hline Picture naming & $12(75)$ & $16(100)$ & $1 / 6$ & $(0.0 \pm 0.14)$ \\
\hline \multicolumn{5}{|l|}{ Primary visual functions } \\
\hline Discrimination of line length & $2(20)$ & $6(75)$ & $/ 10$ & $(0.0 \pm 0.00)$ \\
\hline Counting points & $3(50)$ & $4(67)$ & 16 & $(0.0 \pm 0.00)$ \\
\hline Perception of oblique lines & I (I7) & $4(67)$ & 16 & $(0.1 \pm 0.64)$ \\
\hline Discrimination of piling figures & $6(100)$ & $6(100)$ & 16 & $(0.1 \pm 0.40)$ \\
\hline \multicolumn{5}{|l|}{ Recognition of symbols } \\
\hline Recognition of cartographic symbols & $2(25)$ & $8(100)$ & 18 & No mean $\pm S D$ for this item \\
\hline Reading characters & $11(17)$ & - & 166 & \\
\hline Katakana & $0(0)$ & $6(100)$ & 16 & $(0.0 \pm 0.00)$ \\
\hline Hiragana & $2(17)$ & $12(100)$ & $1 / 2$ & $(0.0 \pm 0.27)$ \\
\hline Kanji & $2(17)$ & $12(100)$ & $/ 12$ & $(0.1 \pm 0.14)$ \\
\hline Figures & I (8) & $12(100)$ & $1 / 2$ & No mean $\pm S D$ for this item \\
\hline Words (kanji) & $4(33)$ & - & $1 / 2$ & No mean $\pm S D$ for this item \\
\hline Words (kana) & $2(17)$ & - & $1 / 2$ & No mean $\pm S D$ for this item \\
\hline \multicolumn{5}{|l|}{ Hemispatial neglect } \\
\hline Checking the center of lines & $19.3 \%$ to the left & - & & \\
\hline
\end{tabular}

Notes: A dash (-) rather than a number indicates patient found task too difficult; mean \pm SD of normal controls. ${ }^{8}$ Abbreviation: SD, standard deviation. 


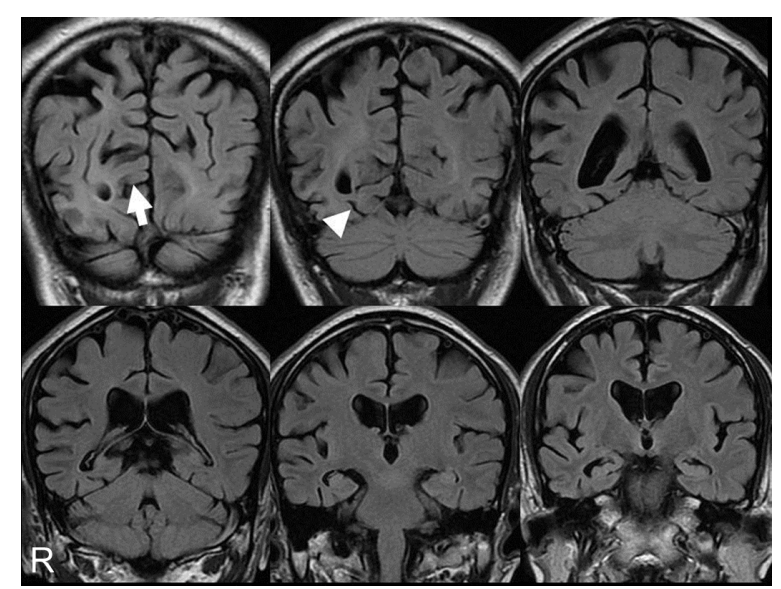

Figure I Magnetic resonance imaging coronal sections of fluid-attenuated inversion recovery images on first examination. The calcarine sulcus (arrow) and collateral sulcus (arrow head) were broader on the right than the left. The finding was temporo-parieto-occipital lobe atrophy with right-side dominance.

the inferior lateral temporal lobe to the lateral occipital lobe (Figure 2). ${ }^{11} \mathrm{C}$-labeled Pittsburgh Compound-B PET showed no accumulation of amyloid beta in the cerebral cortex. Eleven months after the first examination magnetic resonance imaging (Figure 4) and SPECT using eZIS ${ }^{10}$ (Figure 5) showed progression of temporo-parieto-occipital lobe atrophy with right-side dominance. The visual perception tests for agnosia and MMSE were retested 14 months after our first examination: the patient completed no task correctly with regard to face or object recognition. Previously preserved recognition of symbols was also lost. His ability on primary visual functions like perception of line length was also impaired. The MMSE score was $24 / 30$ with errors in orientation to time ( -1 point), recall ( -1 point), reading

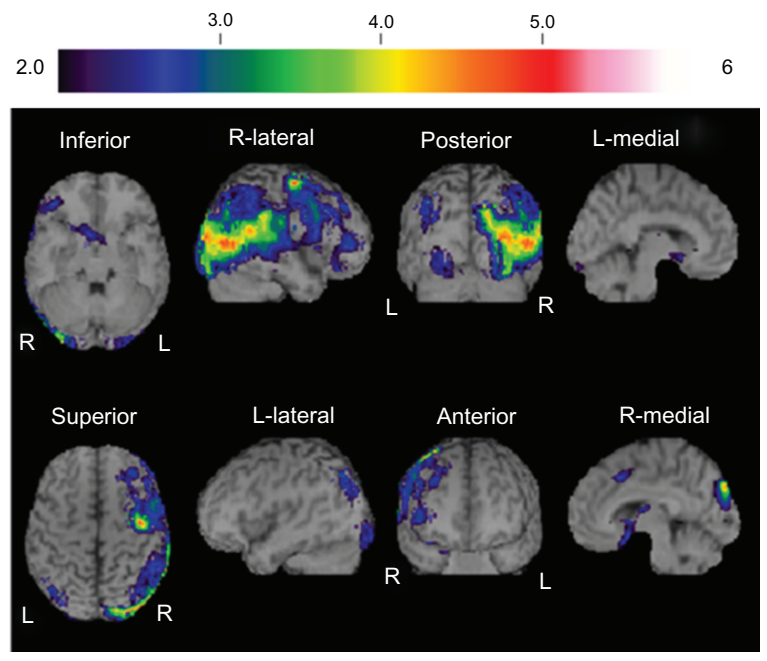

Figure $2{ }^{99 m}$ Tc-ethyl cysteinate dimer SPECT using eZIS ${ }^{10}$ on first examination showed decreased blood flow in the temporo-parieto-occipital lobe with right-side dominance.
( -1 point), complex commands ( -3 points), and copying of a double pentagon. He also now showed Bálint's syndrome, and failed to register the presence of members of medical staff until they spoke. On occasions he could distribute letters to family members by reading names on envelopes. All these observations were noted 14 months after our first meeting. We believe our patient met the criteria for dementia at the second evaluation, because he had cognitive dysfunctions in a number of regions as shown by MMSE, and was unable to continue working. The Barthel Index ${ }^{8}$ score was $60 / 100$ because he needed help managing activities that involved visual ability. Furthermore, he gradually showed rigidity of the left wrist. Other Parkinsonism was not confirmed.

\section{Discussion}

We have described a patient with progressive prosopagnosia whose visual symptoms were identified using the visual perception test for agnosia, ${ }^{8}$ a test standardized in 1995 using 335 Japanese subjects. The clinical diagnosis was PCA.

PCA was named by Benson et al. ${ }^{11}$ It is an atypical dementia with lesion confined to the posterior association area. Visual dysfunction is a primary symptom, but there is no memory disturbance at an earlier stage. Primary visual dysfunction is now accepted as symptomatic of PCA. ${ }^{4}$

Bodamer ${ }^{12}$ first named prosopagnosia on the basis of cerebrovascular disease, or trauma. More recently, activation studies with normal subjects have established the "fusiform face area" as important to face recognition. ${ }^{13} \mathrm{We}$ also confirmed the importance of the fusiform face area in an earlier paper on autopsy of cerebral infarction with prosopagnosia. ${ }^{14}$

Progressive prosopagnosia has been linked to localized cortical degeneration similar to progressive aphasia: Tyrrell et $\mathrm{al}^{2}$ and Evans et al. ${ }^{1}$ Gentileschi et al, ${ }^{15}$ Gainotti et al, ${ }^{16}$ and Joubert et $\mathrm{al}^{17}$ also reported cases of progressive prosopagnosia. These cases could not recognize familiar faces, but had almost intact primary face perception skills, so the symptoms were diagnosed as being part of associative prosopagnosia. ${ }^{7}$ The reported lesions were also similar to right temporal lobe atrophy. These suggest that progressive associative prosopagnosia with right temporal atrophy is in contrast to progressive aphasia with left temporal atrophy in semantic dementia. ${ }^{1}$

We believe our PCA case is an example of apperceptive prosopagnosia (Figure 3) due to the patient's inability to: (1) discriminate and match unfamiliar faces, (2) recognize facial expressions, and (3) discriminate sex and age, while (4) retaining primary visual function. PCA is currently 


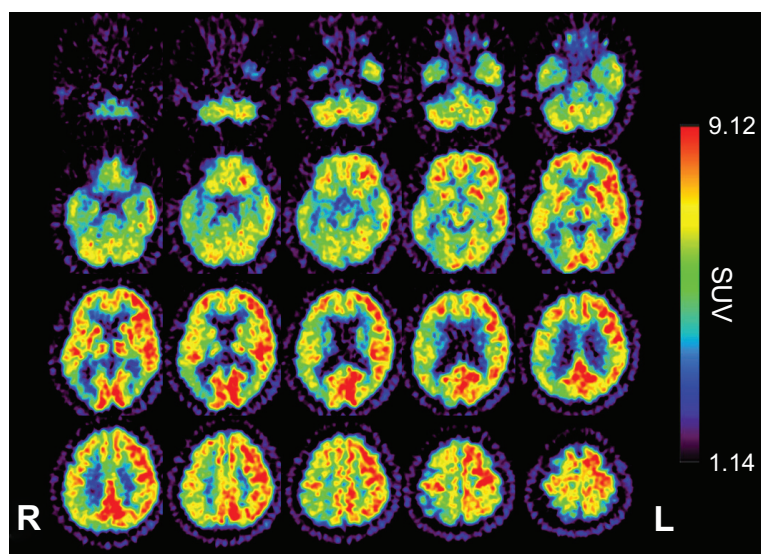

Figure $3{ }^{18} \mathrm{~F}$-fluorodeoxyglucose positron emission tomography, 7 months after first examination, showing hemihypometabolism, especially from the inferior lateral temporal lobe to the lateral occipital lobe.

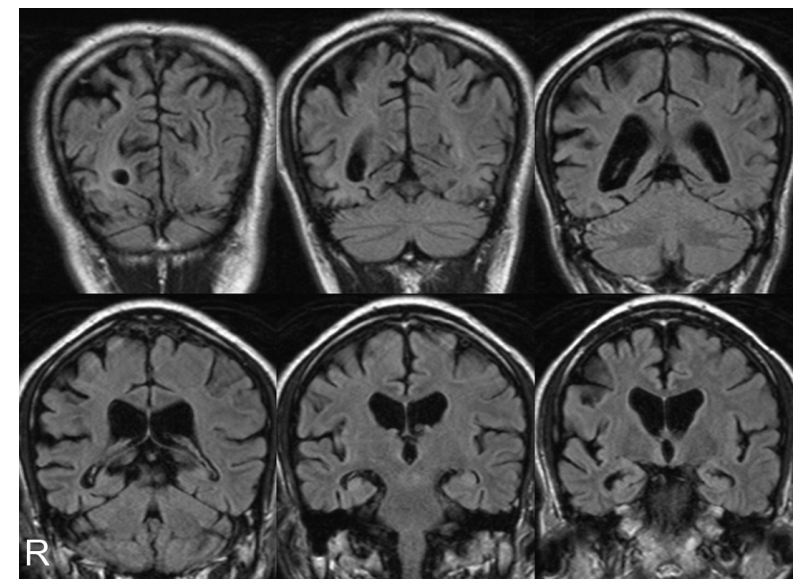

Figure 4 Magnetic resonance imaging coronal sections of fluid-attenuated inversion recovery images II months after first examination showed progression of temporoparieto-occipital lobe atrophy with right-side dominance.

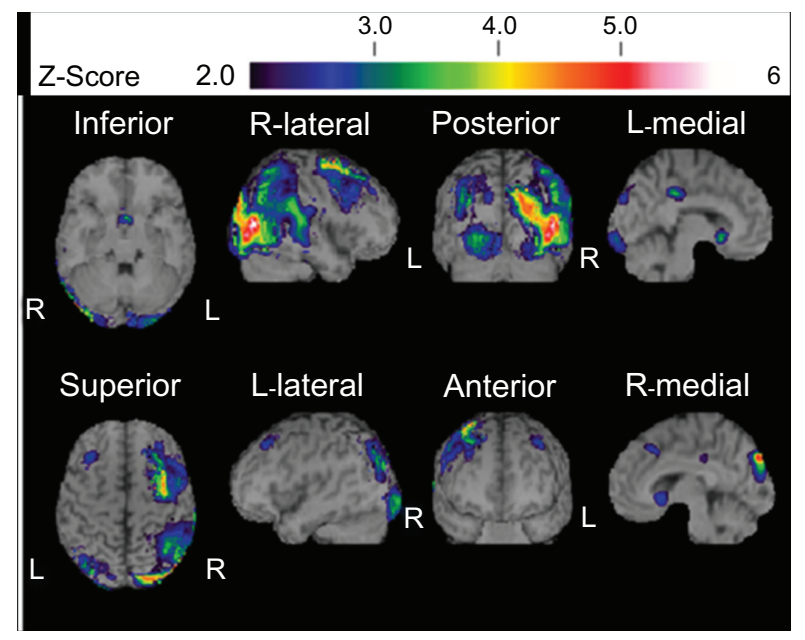

Figure $5^{99 m}$ Tc-ethyl cysteinate dimer SPECT using the eZIS ${ }^{10}$ II months after first examination showed decreased blood flow in the temporo-parieto-occipital lobe with right-side dominance. considered a degenerative disease with the prosopagnosia secondary to enlargement of the lesion from the dorsal to the ventral visual pathway. ${ }^{4,5}$ However, PCA may present apperceptive prosopagnosia with more primary visual dysfunctions linked to posterior cerebral atrophy. In the visual pathway, perception and recognition proceed from the occipital to the temporal (ventral pathway), or to the parietal lobe (dorsal pathway). Simultaneously they integrate with other modalities, or match to memory. There is functional evidence, therefore, for the progressive prosopagnosia of frontotemporal lobar degeneration to be regarded as associative,,$^{1,2,15-17}$ while that of PCA is apperceptive.

PCA presents mainly dorsal visual stream dysfunction. ${ }^{4}$ While most PCA cases show Alzheimer disease pathology, the anatomical evidence is parietal-occipito-temporal. ${ }^{5}$ The patient we describe here had ventral type PCA with prosopagnosia with no evidence of amyloid beta accumulation as indicated by Pittsburgh Compound-B-PET. Furthermore, our patient showed symptoms of atrophy that were right dominant. He also had gradual rigidity of the left wrist. And while it is possible he had a tauopathy, such as corticobasal degeneration, he did not have Alzheimer's disease. ${ }^{5}$

We believe this may be a first case of primary progressive prosopagnosia of ventral PCA with right dominancy. If so, it adds to the evidence for ventral PCA with left dominancy reported by Beversdorf and Heilman. ${ }^{6}$ The Beversdorf case

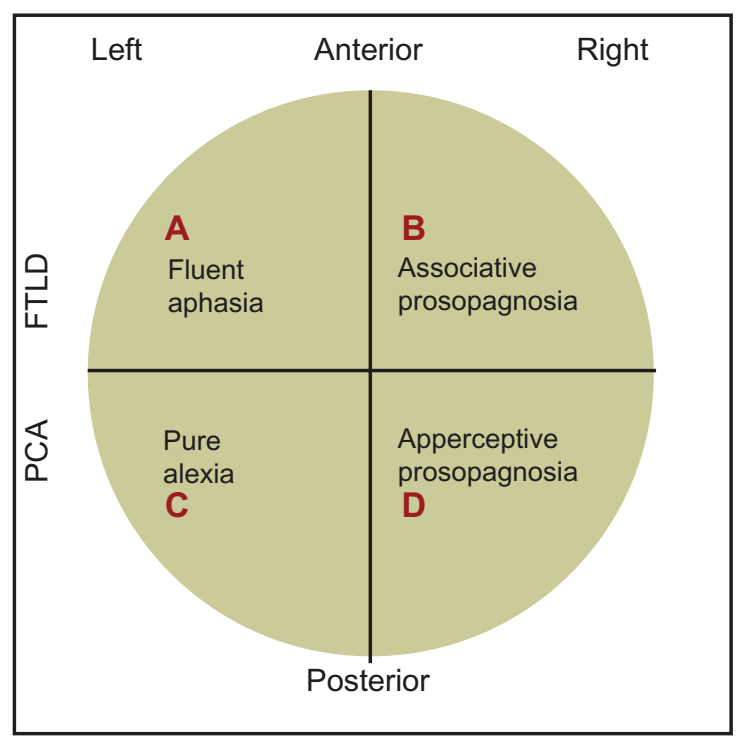

Figure 6 A simple, schematic diagram of the relative loci of associative and apperceptive prosopagnosia, fluent aphasia, and pure alexia. Our own case history of PCA/apperceptive prosopagnosia relates to area $D$ in the ventral part of the right posterior area of the brain.

Abbreviations: PCA, posterior cortical atrophy; FTLD, frontotemporal lobar degeneration. 
presented alexia, and had visual agnosia for music and words with left dominancy.

To summarize these findings and our hypothesis, we provide a simple schematic diagram showing the relative loci of associative and apperceptive prosopagnosia, fluent aphasia, and pure alexia (Figure 6). If our own findings are accurate, then our case history of PCA/apperceptive prosopagnosia will relate to area $\mathrm{D}$ in the model: that is to the ventral region of the right posterior area of the brain.

\section{Acknowledgments}

Supported by the Tamagawa University Center of Excellence under the Ministry of Education, Culture, Sports, Science and Technology (MK); Core Research for Evolutionary Science and Technology (CREST 17022035); a Grant-in-Aid for Scientific Research on Innovative Areas, "Face perception and recognition," from MEXT (21119518); a Grant-in-Aid for Scientific Research on Priority Areas - System Study on High-Order Brain Functions from Showa University Grant-inAid for Innovative Collaborative Research Projects; a Special Research Grant-in-Aid for Development of Characteristic Education from MEXT; a Grant-in-Aid for Comprehensive Research on Dementia (No 1103404) from the Ministry of Health, Labor, and Welfare of Japan (KeI).

\section{Disclosure}

The authors report no conflicts of interest in this work.

\section{References}

1. Evans JJ, Heggs AJ, Antoun N, Hodges JR. Progressive prosopagnosia associated with selective right temporal lobe atrophy. A new syndrome? Brain. 1995;118(Pt 1):1-13.

2. Tyrrell PJ, Warrington EK, Frackowiak RS, Rossor MN. Progressive degeneration of the right temporal lobe studied with positron emission tomography. J Neurol Neurosurg Psychiatry. 1990;53(12):1046-1050.
3. Hodges JR, Patterson K, Oxbury S, Funnell E. Semantic dementia Progressive fluent aphasia with temporal lobe atrophy. Brain. 1992;115(Pt 6):1783-1806.

4. McMonagle P, Deering F, Berliner Y, Kertesz A. The cognitive profile of posterior cortical atrophy. Neurology. 2006;66(3):331-338.

5. Tang-Wai DF, Graff-Radford NR, Boeve BF, et al. Clinical, genetic, and neuropathologic characteristics of posterior cortical atrophy. Neurology. 2004;63(7):1168-1174.

6. Beversdorf DQ, Heilman KM. Progressive ventral posterior cortical degeneration presenting as alexia for music and words. Neurology. 1998;50(3):657-659.

7. De Renzi E, Faglioni P, Grossi D, Nichelli P. Apperceptive and associative forms of prosopagnosia. Cortex. 1991;27(2):213-221.

8. Mahoney FI, Barthel DW. Functional evaluation: the Barthel index. Md State Med J. 1965;14:61-65.

9. Japan Society for Higher Brain Dysfunction. Visual Perception Test for Agnosia. Tokyo, Japan: Shinkoh Igaku Shuppan; 1998 (in Japanese).

10. Mizumura S, Kumita S. Stereotactic statistical imaging analysis of the brain using the easy Z-score imaging system for sharing a normal database. Radiat Med. 2006;24(7):545-552.

11. Benson DF, Davis RJ, Snyder BD. Posterior cortical atrophy. Arch Neurol. 1988;45(7):789-793.

12. Bodamer J. Die prosopagnosia. Arch Psychiatr Nervenkr. 1947;179: $6-53$.

13. Kanwisher N, McDermott J, Chun MM. The fusiform face area: a module in human extrastriate cortex specialized for face perception. J Neurosci. 1997;17(11):4302-4311.

14. Sugimoto A, Miller MW, Kawai Y, Shiota J, Kawamura M. Another piece in the jigsaw: a case report of prosopagnosia with symptomatological, imaging and post mortem anatomical evidence. Cortex. 2011. [Epub ahead of print.]

15. Gentileschi V, Sperber S, Spinnler H. Crossmodal agnosia for familiar people as a consequence of right infero polar temporal atrophy. Cogn Neuropsychol. 2001;18(5):439-463.

16. Gainotti G, Barbier A, Marra C. Slowly progressive defect in recognition of familiar people in a patient with right anterior temporal atrophy. Brain. 2003;126(Pt 4):792-803.

17. Joubert $\mathrm{S}$, Felician $\mathrm{O}$, Barbeau E, et al. Progressive prosopagnosia: clinical and neuroimaging results. Neurology. 2004;63(10):1962-1965.
Neuropsychiatric Disease and Treatment

\section{Publish your work in this journal}

Neuropsychiatric Disease and Treatment is an international, peerreviewed journal of clinical therapeutics and pharmacology focusing on concise rapid reporting of clinical or pre-clinical studies on a range of neuropsychiatric and neurological disorders. This journal is indexed on PubMed Central, the 'PsycINFO' database and CAS

\section{Dovepress}

The manuscript management system is completely online and includes a very quick and fair peer-review system, which is all easy to use. Visit http://www.dovepress.com/testimonials.php to read real quotes from published authors. 